\title{
Narrativas na formação de estudantes de medicina: relatos de experiências
}

\author{
Narratives in the training of medical students: experience reports \\ Narrativas en la formación de estudiantes de medicina: relatos de experiência
}

\author{
Denise Espírito Santo ${ }^{1}$ \\ Eloísa Grossman ${ }^{2}$ \\ Fátima Geovanini ${ }^{3}$ \\ Luciana Andrade ${ }^{3}$ \\ Maria Tereza Fonseca da Costa ${ }^{3}$ \\ Viviane Manso Castello Branco ${ }^{4}$
}

Resumo: O estudo das narrativas tem recebido considerável atenção nas ciências humanas e sociais há algum tempo. Na medicina, o estudo das narrativas e a preocupação com a formação de profissionais com essa competência são mais recentes, nos últimos anos. Tem alcançado maior destaque no ensino médico, como estratégia pedagógica fundamental para a humanização da assistência à saúde da população. Os autores apresentam suas experiências em disciplinas curriculares e eletivas em diferentes escolas de medicina da cidade do Rio de Janeiro.

Palavras chave: Medicina Narrativa; Educação Médica; Humanidades

\begin{abstract}
The study of narratives has received considerable attention in the humanities and social sciences for some time. In medicine, the study of narratives and the concern with training professionals with this competence are more recent, in recent years, it has achieved greater prominence in medical education, as a fundamental pedagogical strategy for the humanization of health care for the population. The authors present their experiences in curricular and elective subjects in different medical schools in the city of Rio de Janeiro.
\end{abstract}

Keywords: Narrative Medicine; Education, Medical; Humanities

Resumen: El estudio de las narrativas ha recibido una atención considerable en las humanidades y las ciencias sociales durante algún tiempo. En medicina, el estudio de las narrativas y la preocupación por formar profesionales con esta competencia son más recientes, en los últimos años. Ha logrado un mayor protagonismo en la educación médica, como estrategia pedagógica fundamental para la humanización de la atención de la salud de la población. Los autores presentan sus experiencias en materias curriculares y optativas en diferentes facultades de medicina de la ciudad de Río de Janeiro. Palabras clave: Medicina Narrativa; Educación Médica; Humanidades

\footnotetext{
${ }^{1}$ Instituto de Artes / Programa de Pós-graduação em Artes, Universidade do Estado do Rio de Janeiro Rio de Janeiro, Brasil

${ }^{2}$ Faculdade de Ciências Médicas da Universidade do Estado do Rio de Janeiro, Rio de Janeiro, RJ, Brasil

${ }^{3}$ Curso de Medicina da Universidade Estácio de Sá, Rio de Janeiro, Brasil

${ }^{4}$ Escola de Medicina da Fundação Técnico-Educacional Souza Marques, Rio de Janeiro, RJ, Brasil
} 


\section{Introdução}

Em nosso cotidiano sempre estaremos em contato com o ato narrativo, quer seja como ouvintes ou como agentes ativos da criação de uma narrativa. Profissionais de saúde estão frequentemente co-criando histórias com colegas de equipe, estudantes, pacientes, famílias e comunidades. Médicos e professores de escolas médicas estão imersos no ato de ouvir e contar histórias; a narrativa é o fundamento da semiologia e da difusão do saber médico. Paulo Freire ${ }^{5}$ diz que a leitura verdadeira nos compromete com o texto que nos é dado e para o qual nos doamos e de cuja compreensão nos vamos tornando também sujeitos. Por analogia, esse mesmo compromisso acontece com as histórias que nos são oferecidas em troca de cuidado.

Charon $^{6}$ introduziu o termo Medicina narrativa e definiu a importância da competência narrativa no cuidado das pessoas. Esse movimento deu grande impulso ao reconhecimento de sua importância na clínica, definindo-a como aquela que é praticada com a competência narrativa para reconhecer, interpretar e ser levado a agir pela situação crítica dos outros.

As Diretrizes Curriculares Nacionais $\left(2001^{7}\right.$ e $\left.2014^{8}\right)$ preconizam a inclusão de dimensões éticas e humanísticas nos cursos de medicina, explicitando como eixos fundamentais a humanização do cuidado, a comunicação com empatia com pacientes, familiares e equipe, dentre outras propostas, que em síntese, compõem um perfil de egresso com formação geral, humanista, crítica, reflexiva e ética.

Algumas escolas iniciaram mais precocemente processos de renovação de seus projetos pedagógicos em consonância com as Diretrizes Curriculares Nacionais de $2001^{3}$, outras mais tardiamente.

As experiências aqui apresentadas apontam para a possibilidade de busca de diferentes caminhos e formatos, consonantes com os projetos de cada escola e com as trajetórias, experiências de formação e profissionais dos docentes, bem como, em função das parcerias estabelecidas.

\footnotetext{
${ }^{5}$ Paulo Freire, Pedagogia da autonomia: saberes necessários à prática educativa (Rio de Janeiro: Editora Paz e Terra, 2013), 29.

${ }^{6}$ Rita Charon, "Narrative Medicine: a Model for Empathy, Reflection, Profession and Trust", JAMA 286 (2001), 1897-1902.

${ }^{7}$ Brasil. Ministério da Educação. Parecer CNE/CES 4, de 7 de novembro de 2001. Diretrizes Curriculares Nacionais do Curso de Graduação em Medicina.

${ }^{8}$ Brasil. Ministério da Educação. Parecer CNE/CES 116, de 3 de abril de 2014. Diretrizes Curriculares Nacionais do Curso de Graduação em Medicina.
} 


\section{Breve história sobre uma longa parceria entre arte, saúde e educação}

Narrativas imagéticas e/ou visuais constituem uma abordagem pioneira e exitosa para os estudos sobre o inconsciente e as relações entre arte e saúde mental. Uma de suas primeiras defensoras e responsável por uma revolução no campo clínico e no tratamento de pessoas acometidas por transtornos psíquicos foi a Dra. Nise da Silveira9 (1905-1999), fundadora do Museu de Imagens do Inconsciente. Em uma de suas primeiras experiências no Hospital Psiquiátrico do Engenho de Dentro, para onde fora transferida após uma breve passagem pelo Manicômio de Pedro II, dirigido pelo médico Juliano Moreira, Dra. Nise recusou-se a aplicar um eletrochoque em um paciente, recusa essa que significou o início de um trabalho com os internos do hospital, que ela sabiamente nomeou como "terapia ocupacional", ressignificando completamente o que o termo designava como trabalhos manuais e muitas vezes, trabalho não remunerado realizado pelos internos dos hospitais e manicômios psiquiátricos.

O trabalho da Dra. Nise, absolutamente singular para um conjunto de saberes vinculados ao tema da loucura, das artes, da clínica e da crítica, representa um divisor de águas para as correntes da psiquiatria e veio a ser um dos principais vetores para a Reforma Psiquiátrica, para o surgimento da psiquiatria social e outras abordagens que cresceram a partir da segunda metade do século XX não só no Brasil, mas também no mundo inteiro.

Se o trabalho com a arte em suas diferentes linguagens, técnicas e procedimentos fez dos ateliês localizados no Hospital Psiquiátrico do Engenho de Dentro, um grande laboratório para o acesso às imagens que povoam os "inumeráveis estados do ser", como a Dra. Nise entendia o espectro da loucura em muitos dos seus "clientes", por outro lado, esse trabalho inaugurou um campo disciplinar novo que vem contribuindo para os estudos da linguagem, para as teorias da cognição, para as possibilidades de contato entre o que nomeamos como mundo e o que jaz submerso a este. Por outro lado, há que se considerar também que o trabalho com arte nos ateliês do Engenho de Dentro contribuiu para o surgimento de grandes artistas, poderíamos até dizer de talentos extraordinários que hoje são reconhecidos dentro do próprio circuito da arte brasileira contemporânea.

Em meados de 2013, quando uma das autoras desse artigo foi procurada pelo professor Pavão, médico e na época diretor da Unidade Docente de Atendimento Psiquiátrico do HUPE para uma

\footnotetext{
${ }^{9}$ Localizado no Hospital do Engenho de Dentro, Rio de Janeiro, o Museu de Imagens do Inconsciente foi criado pela Dra. Nise da Silveira em 1946, junto à Seção de Terapêutica Ocupacional. Dentre as diferentes atividades realizadas como pintura, desenho, escultura e modelagem, o trabalho com arte revelou-se como um meio excepcional de acesso ao mundo das imagens dos pacientes. Para maiores informações, acessar: http://mii2.hospedagemdesites.ws/
} 
parceria com o Instituto de Artes da UERJ, que redundou na criação do primeiro ateliê de artes na Vila da Psiquiatria, descobriu-se que havia ali um interesse recíproco, acenando para a criação de um novo laboratório voltado para os pacientes acompanhados semanalmente no ambulatório daquela unidade de saúde. Construímos então, com a ajuda do professor Aldo Victorio, um grupo de trabalho formado inicialmente por estudantes de Artes Visuais e Medicina, Residentes, Assistente Social e outros profissionais da saúde. Não demorou muito para que encontrássemos na modelagem e na cerâmica o caminho ideal para a criação deste ateliê, que após a conquista de um edital Faperj possibilitou a criação de um novo laboratório bem equipado, contando com ceramistas auxiliados pelo grupo de trabalho. Seguiram-se outras ações relativas a esse projeto: o Seminário Arte e Loucura, ocorrido no Instituto de Artes em 2015, recebeu convidados importantes que configuram a história das políticas públicas no campo da saúde mental no Brasil, além de despertar nos estudantes de artes e medicina igual interesse.

Como se pode observar, nossa singela contribuição para o prosseguimento dessa pesquisa que procura descortinar as relações, diálogos, aproximações e contágios entre as áreas da arte, saúde, educação, deve-se sobretudo a um aspecto molecular de toda atividade artística e também criativa, ou seja, a partilha do sensível segundo Ranciére ${ }^{10}$. Pensado como plataforma movente que se desloca por muitos outros espaços, ampliamos o raio dessa experiência em 2018, quando aportamos com nosso ateliê itinerante no NESA - Núcleo de Estudos da Saúde do Adolescente, outra unidade de saúde do Hospital Universitário Pedro Ernesto, da UERJ, oferecendo oficinas de artes plásticas para o público infanto-juvenil, seus pais e responsáveis. Mais uma vez, nos deparamos com a recepção favorável deste trabalho no cotidiano daquela clínica e nos surpreendemos com os "efeitos curativos" que essas oficinas proporcionam, nos desafiando a escrever sobre essa experiência, acolher outras pesquisas semelhantes e abrir-nos para uma experiência curricular que acabou aportando na Faculdade de Medicina da UERJ, mas essa história levamos para o próximo parágrafo.

Foi a partir de um encontro com a professora Eloísa Grossman, da Faculdade de Medicina, e o professor Aldo Victorio, do Instituto de Artes, que a disciplina "Corpo, cultura, imagem" começou a ser elaborada como uma possibilidade de germinação deste debate do corpo, das suas epistemologias, como um tema central para incitar uma pequena abertura, no sentido de ampliar os referenciais conceituais, filosóficos, estéticos do corpo em contextos curriculares tão distintos, quanto o da medicina e das artes. Em linhas gerais a disciplina se propõe a "problematizar o corpo, sua história e

\footnotetext{
${ }^{10}$ Jacques Ranciére, A partilha do sensível (São Paulo: Editora 34, 2009).
} 
padrões, como resultante de múltiplas relações biológicas, biopolíticas, estéticas, culturais e ambientais". Contudo, aspectos como a produção de si como realização poética, a autoimagem individual e coletiva, os processos identitários e os processos instituidores das igualdades e das diferenças são abordados e discutidos junto aos estudantes, recorrendo dentre fontes diversas à história da representação dos corpos na Arte e demais instâncias da Cultura Visual. Em nossos encontros fomentamos o interesse por um vastíssimo repertório de imagens que constituem narrativas significativas para a compreensão da rede complexa que opera o corpo, a sociedade, a linguagem, e os dispositivos contemporâneos, daí valorizarmos nesta fase de implementação da disciplina os relatos que nos chegam ao final de cada semestre, que procuram subsidiar essa pesquisa e aprimorar os conteúdos nela implicados. Ao longo dos 2 últimos semestres a disciplina reuniu alguns comentários atribuídos aos estudantes dos cursos de artes e medicina que são dignos de registro pela abertura que essa abordagem inspira no tocante aos currículos e à formação desses futuros profissionais:

\footnotetext{
Sair do automatismo corporal e expressivo sempre foi algo difícil para mim... Foi através dessa disciplina que consegui transpor algumas barreiras antigas autoimpostas e que se obstruíram ainda mais com a pandemia...

De antemão, eu quero considerar uma palavra-chave no intuito de expressar o que a disciplina significou para mim: autoconhecimento... cada aluno expôs sua avaliação com base em suas experiências vividas... Com base no que acabei de dizer, essa disciplina despertou mais ainda minha condição humana rumo à descoberta de quem realmente eu sou. E essa busca é por toda a vida...
}

\section{A disciplina Competência narrativa na prática médica}

Na face do velho

as rugas são letras,

palavras escritas na carne,

abecedário do viver.

(Conceição Evaristo)

Há abundante literatura sobre os argumentos que justificam uma mudança radical no currículo da escola médica tradicional. O foco dos cuidados de saúde deslocou-se das condições agudas para as condições crônicas de adoecimento e do hospital para a comunidade. A centralidade do aluno substituiu a centralidade do professor e a tecnologia implicou em mudanças nas formas de cuidar e de ensinar.

Instigados por essa necessidade, em 2018 participamos da discussão e implementação de um novo projeto político-pedagógico e de uma nova versão do currículo da Faculdade de Ciências Médicas, da Universidade do Estado do Rio de Janeiro. A disciplina integradora Competência narrativa 
na prática médica foi incluída na grade curricular do curso, no quarto semestre, inserida no eixo das Humanidades médicas. Resultou de uma convicção e de uma perplexidade; de uma convicção da importância da história clínica e da semiologia no raciocínio clínico e da perplexidade de perceber a progressiva desvalorização dessa importância, bem como, a dificuldade crescente dos alunos em integrar diferentes conhecimentos estudados de forma fragmentada.

A disciplina foi desenhada a partir da discussão com professores e estudantes, através de um diálogo franco de aprendizagem mútua. Na disciplina não são apresentadas fórmulas, são oferecidas ferramentas que visam contribuir para melhorar a competência dos alunos em juntar informações (orais, escritas e imagens) para criar histórias e, ao mesmo tempo, saber como transformar essas histórias em narrativas médicas, imprescindíveis para a discussão dos casos particulares e para o levantamento de hipóteses diagnósticas. Para exercer seu ofício de forma adequada, médicos precisam integrar conhecimentos e, do resultado, deduzir coisas diferentes do que sua mera adição.

Histórias só existem quando são contadas. Narrar é uma das manifestações da nossa humanidade, uma das formas pelas quais procuramos sentido para a nossa existência e ensaiamos respostas para as nossas perplexidades ${ }^{11}$. As pessoas que procuram cuidados médicos necessitam compartilhar suas experiências, percepções e medos. Para que isso aconteça, precisam sentir-se seguras e ter a percepção de que há um ouvinte interessado nas várias histórias simultâneas que vêm à memória, muitas vezes em desordem. Essa relação de afeto, proximidade e lealdade é diametralmente oposta a uma pretensa neutralidade, que ganha eco em alguns discursos sobre a prática profissional do médico. A partir do vínculo de confiança construído é possível selecionar, combinar, fazer arranjos, dando para o disperso uma sintaxe. Por outro lado, é fundamental que através de um processo de autoconhecimento não sejam abafadas com o slogan da igualdade a grande força política das diferenças das diferenças que importam e que constituem as pessoas e das diferenças que foram forjadas e as excluem de direitos e de acesso, relativas a raças, grupos, gêneros e orientações de vontades, desejos e gostos ${ }^{12}$.

Para alcançar os objetivos de aprendizagem elencados, foi proposto o envolvimento da arte na educação médica, através da utilização de narrativas literárias, fragmentos de filmes e artes visuais. Apostamos no potencial da arte em promover reflexão, interpretação e imaginação; em facilitar a autoconsciência; em estimular o envolvimento afetivo e em auxiliar a lidar com a ambiguidade e a

\footnotetext{
${ }^{11}$ Teresa Casal, Narrativa e Medicina: A Perspectiva da Primeira Pessoa no Encontro Clínico. In: Narrativa e Bioética, org. António Barbosa. (Lisboa: Faculdade de Medicina de Lisboa: Centro de Bioética; 2015), 60.

${ }^{12}$ Roberto Correa Santos, Modos de saber, modos de adoecer: o corpo, a arte, o estilo, a história, a vida, o exterior (Belo Horizonte: Ed. UFMG, 1999), p.58.
} 
compreensão mais sutil e profunda ${ }^{13}$. Dentre as atividades propostas destacam-se a escrita criativa a partir da leitura de textos literários, pinturas, fotografias, músicas e filmes e de disparadores prédefinidos, assim como, o compartilhamento das narrativas e discussão em pequenos grupos. A disciplina tem a carga horária de 40 horas e integra professores das disciplinas de Clínica médica; Psicologia Médica; Farmacologia e Medicina Integral, Familiar e Comunitária. É dividida em módulos: a narrativa na prática clínica; a narrativa das imagens médicas; as narrativas e a competência cultural; e a voz do paciente e de seus familiares - as narrativas em primeira pessoa. Transversalmente, em todos os módulos é dada ênfase às narrativas do cuidado na clínica, bem como, à relação médicopaciente/ familiares, médico e equipe de saúde, estudante e professor/preceptor. A escolha dos materiais utilizados é dinâmica, rediscutida a cada versão, e não necessariamente tem a obrigatoriedade de versar sobre experiências de adoecimento. A arte é utilizada para permitir aos estudantes a aproximação com a experiência do outro, permitindo o contato com mundos antes desconhecidos.

A disciplina foi oferecida pela primeira vez em 2019. A pandemia da COVID-19 determinou a busca de soluções num momento de tantas incertezas. Em poucos meses, a disciplina foi reconfigurada para o ensino remoto, apoiado nas plataformas digitais, através de uma proposta de desenvolvimento de atividades síncronas e assíncronas. A partir de uma avaliação preliminar, identificamos que, apesar das inúmeras dificuldades e da insegurança, as atividades propostas e os feedbacks oferecidos após a sua realização envolveram professores e estudantes em um procedimento significativo de aprendizagem. Observamos, ainda, a necessidade de melhor exploração das possibilidades de comunicação da comunidade de aprendizagem.

Para concluir, tomo por empréstimo as palavras de uma aluna: Tudo na vida é uma narrativa, a própria vida em si é uma. A medicina narrativa para mim é a habilidade que o médico tem de fazer uma escuta ativa, observação cuidadosa aos sinais não verbais e criar um nexo entre essas características. Elas nos fazem acreditar que o desenvolvimento de competência narrativa está associado a um cuidado médico mais ético e menos fragmentado, bem como, a um maior crescimento pessoal e profissional dos estudantes de medicina.

\footnotetext{
${ }^{13}$ Paul Haidet et al., "A guiding framework to maximise the power of the arts in medical education: a systematic review and metasynthesis", Med Educ 50, 3 (2016): 320.
} 


\section{Narrativas no cotidiano da sala de aula e dos campos de prática do primeiro ano}

Tudo pode ser página. Depende apenas da intenção de descoberta do nosso olhar. Queixamo-nos de que as pessoas não leem livros. Mas o déficit de leitura é muito mais geral. Não sabemos ler o mundo, não lemos os outros. (Mia Couto).

A Escola de Medicina Souza Marques insere todos os alunos do primeiro ano nos campos de prática, por meio da Disciplina de Medicina Social. Após um período de formação, os estudantes desenvolvem atividades de observação e promoção da saúde em escolas públicas e unidades de saúde. Além dos conteúdos especificamente relacionados à Saúde Coletiva, as docentes buscam potencializar o desenvolvimento de habilidades e atitudes que contribuam para a formação humanística.

A preparação dos estudantes para as atividades práticas envolve dinâmicas e técnicas, como os jogos do Teatro do Oprimido, que trabalham relações de poder, criatividade, escuta ativa e desenvolvimento de potencialidades. Filmes, vídeos, séries, animações, letras de músicas, textos literários, poesias, fotografias, cartuns, obras de arte, são usados de diferentes formas para ampliar o olhar e estimular a sensibilidade, a criatividade, o pensamento simbólico e a capacidade de interpretação. Dessa forma, ajudam a discutir empatia, preconceitos, comunicação, solidariedade e outros aspectos que serão relevantes nas atividades de grupo e na relação com colegas, alunos das escolas e pacientes. Algumas ferramentas da Medicina Narrativa, propostas por Rita Charon ${ }^{\mathbf{1 4}}$, incorporadas recentemente nas aulas online, vêm contribuindo para aprofundar essa reflexão.

As discussões sobre temas que serão trabalhados nas escolas tais como alimentação, cultura da paz e sexualidade incluem diferentes vozes e pontos de vista, propiciadas por materiais como os vídeos elaborados pelos jovens de comunidades populares do RAP da Saúde (Rede de Adolescentes e Jovens Promotores de Saúde), projeto da Secretaria Municipal de Saúde-RJ e do Centro de Promoção da Saúde, Cedaps. Eventualmente, os próprios jovens do RAP da Saúde são convidados para debates em sala de aula. O documentário Janela da Alma; trechos da série Grey's Anatomy; programas de TV Aquela Conversa (MultiRio); trailers da Maria Farinha Filmes; vídeos dos canais Ter.a.pia, Jout Jout de Saia e outros que estejam circulando nas redes sociais são exemplos de materiais utilizados para reflexão em dinâmicas diversas. Estas estratégias trazem à tona vivências dos próprios alunos, favorecendo a expressão de emoções, o autoconhecimento, o senso crítico e a troca de experiências.

\footnotetext{
${ }^{14}$ Rita Charon et al., The Principles and Practice of Narrative Medicine (New York, NY: Oxford University Press, 2017), $42-59$.
} 
O primeiro trabalho de campo é uma pesquisa sobre os bairros da área da faculdade e dos cenários de prática localizados no subúrbio carioca. Os estudantes fazem entrevistas presenciais ou por meio das redes sociais para conhecer o discurso dos moradores sobre os bairros. Eles se encantam com as histórias, os diferentes personagens e reveem ideias preconcebidas. Dessa forma, começam a compreender um pouco das condições de vida da população com a qual terão contato nas escolas e unidades de saúde.

As atividades incluem também visitas a museus. Merece destaque o Museu de Arte do Rio, MAR, porque o acervo e as exposições temporárias permitem repensar a cidade, sua história e seus habitantes, em especial a população negra. Uma valiosa contribuição é dada pela equipe de mediadores que fazem provocações instigantes, tensionando as percepções dos alunos.

Dentre as narrativas relevantes para a formação dos estudantes, destacam-se aquelas que resultam dos encontros cotidianos nas atividades práticas em escolas e unidades de saúde. Os alunos narram suas reflexões, observações, sentimentos e aprendizados para a vida pessoal e profissional em portfólios reflexivos.

Antes da elaboração das atividades de educação em saúde, os estudantes fazem uma visita à escola onde irão atuar; entrevistam profissionais (diretores, professores, merendeiras etc.) e conversam livremente com os alunos, num diálogo mais horizontal. Conhecem suas histórias de vida, expectativas e trocam experiências. Esse intercâmbio, que acontece nas diversas atividades práticas, traz importantes aprendizados, como demonstram estes depoimentos extraídos dos portfólios. Os nomes são fictícios.

\footnotetext{
"Ver aqueles alunos quase da minha idade, com uma realidade diferente, porém com as mesmas inseguranças e carências, mexeu muito com a minha parte humana". (Ana)

"É o nosso primeiro contato com 'pacientes', momento para aprendermos a escutar, a conversar e, acima de tudo, a respeitar diferenças e opiniões”. (Bento)

A contribuição dessas vivências para a prática médica começa a ficar clara para os alunos:

"Foi muito útil na hora de abordar as pessoas na clínica". (Clara)
}

Para os estudantes do primeiro ano o ponto alto da prática são as atividades na unidade de Atenção Primária e a visita à Maternidade no final do ano. Eles conversam com os pacientes, participam de grupos, de atendimentos com profissionais de diversas áreas e acompanham visitas domiciliares. São também incentivados a observar a relação dos profissionais com os usuários, valorizando a escuta das histórias, as demandas e sentimentos expressados. As percepções dos discentes sobre as diversas narrativas são discutidas em roda ao final de cada manhã e, por vezes, dramatizadas e debatidas. Alguns estudantes se sentem muito tocados por essa experiência. 
"O dia da sala de curativos foi muito significante para mim. Não somente por ter visto as feridas nos pés dos pacientes como todo aspirante a médico, de maneira até um pouco sádica e egoísta, 'gosta'. O mais marcante e enriquecedor foi a conversa com esses pacientes e o contato com a dor de viver com limitações há anos me sensibilizou muito. (...) Houve um momento em que me senti muito privilegiada por poder entrar em contato com essas pessoas como pessoa que não é médica, encarando a situação de outra maneira.” (Dora)

Neste processo, eles se percebem "desenvolvendo a sensibilidade necessária para uma boa prática médica” (Enzo); "tentando se colocar na situação daqueles pacientes” (Flora).

Identificam a necessidade de "prestar atenção no que eles dizem, não necessariamente pelas palavras; a linguagem corporal e a expressão facial podem demonstrar o que eles estão sentindo" (Gina).

Este trabalho impacta positivamente as atividades de educação e saúde que os alunos desenvolvem nas escolas e unidades de saúde, geralmente criativas, sensíveis e cuidadosas. As estratégias descritas podem contribuir para o desenvolvimento de habilidades éticas, empáticas, comunicativas e cooperativas. Para isso, demandam disponibilidade afetiva dos estudantes para se entregarem a novas experiências bem como um esforço das docentes para dar sentido às vivências que, segundo alguns, parecem que "não têm muito a ver com Medicina" (Heitor).

Estas iniciativas valorizam a emoção, afetam as próprias professoras e geram maior conexão entre docentes e discentes. Contribuem para o desenvolvimento de potencialidades e identificação de talentos que talvez não se manifestassem em outros contextos. A Liga de Humanidades, um dos subprodutos deste trabalho, vem sendo um importante elemento multiplicador das Artes na faculdade, por meio do protagonismo, da sensibilidade e da criatividade dos estudantes.

\section{A experiência do uso da literatura e medicina narrativa em uma disciplina eletiva}

No ano de 2012, um grupo diferente se formou no curso de medicina da Universidade Estácio de Sá, que ainda ocupava o campus Arcos da Lapa. Esse grupo, Humanidades, Medicina e Arte, trouxe a proposta de juntar literatura e medicina num projeto único. Com um grupo inicial de 14 alunos e 6 professores iniciou-se um trabalho de leitura de clássicos que resultou num livro, em sua maior parte, escrito pelos alunos participantes e já em sua segunda edição ${ }^{15}$.

Ao longo dos anos após sua criação o grupo passou a integrar algumas disciplinas de teor humanístico do currículo. Assim, essas disciplinas, sejam obrigatórias ou eletivas, são ensinadas por

\footnotetext{
${ }^{15}$ Mallet e Andrade (eds), Literatura e medicina: uma experiência de ensino, (Rio de Janeiro, Livros Ilimitados, 2017).

${ }^{2}$ Ibid
} 
professores do grupo Humanidades, Medicina e Arte. Entre elas estão as disciplinas eletivas Aperfeiçoamento da Linguagem e Sociologia A experiência da utilização da literatura e medicina narrativa em Aperfeiçoamento da Linguagem é trazida aqui.

A disciplina Aperfeiçoamento da Linguagem geralmente é iniciada com a proposta da escolha de um livro a ser lido por todos durante o curso. O livro é escolhido por votos entre os alunos. Os títulos são sugestões das professoras e também dos alunos. Assim, a lista de livros sugeridos varia a cada semestre, em parte porque os alunos trazem novas sugestões, mas também porque costuma-se incorporar títulos de romances recém-lançados. Esse momento de sugestão é rico e gera boa conexão entre todos, de certa forma fazendo uma espécie de apresentação de cada um. É interessante observar que nas sugestões dos alunos sempre estão presentes livros de não-ficção, a grande maioria com caráter de autoajuda. Mas o livro mais votado é aquele com o qual se segue. Os alunos são então divididos em duplas para apresentação de um capítulo por aula. Após a apresentação segue-se uma discussão. Nessa discussão, as professoras tentam sempre incorporar os princípios da medicina narrativa de Rita Charon ${ }^{2}$, colocando, na história lida exemplos de atenção ou escuta atenta, representação e vínculo, o tripé da medicina narrativa.

Para o trabalho com de leitura semestral, sempre há a sugestão de "Todo paciente tem uma história para contar" de Lisa Sanders ${ }^{16}$. Embora o livro traga muito sobre a arte do diagnóstico e aborde muitos casos de doenças raras, Sanders traz a cada capítulo a importância do cuidado na relação entre os profissionais de saúde e os pacientes, além de inúmeros exemplos de sucessos e insucessos ao longo dos anos na prática médica. Por exemplo, ao contar a história de uma médica que tentava descobrir o diagnóstico de uma paciente, ela diz que "a médica se fez a pergunta que todos os médicos devem se formular ao final de uma consulta: o que ela poderia fazer pela paciente naquele dia"?

A experiência de leitura desde a primeira turma da disciplina tem sido sempre diferente. Houve a turma que votou no livro "Intermitências da Morte" de José Saramago 17, uma leitura bastante difícil que costumava ser realizada na própria aula, para que as professoras pudessem explicar as diferentes vozes na narração. Ao final do semestre os alunos encenaram alguns trechos do livro de forma livre, trazendo a história para o contexto do século XXI e ainda produziram um vídeo com fundo musical de Raul Seixas, Canto para minha Morte.

\footnotetext{
${ }^{16}$ Lisa Sanders, Todo paciente tem uma história para contar (Rio de Janeiro, Zahar, 2009, edição brasileira).

${ }^{17}$ José Saramago, As Intermitências da Morte (São Paulo, Companhia das Letras, 2005)
} 
Já outras turmas escolheram títulos como "A Mulher que escreveu a Bíblia" de Moacyr Scliar $^{18}$ ou "O Poder do Agora" de Eckhart Tolle ${ }^{19}$. Com esse último, foi interessante verificar que era possível trazer a discussão para o universo da prática em saúde e até incorporar a algumas situações o tripé da medicina narrativa (escuta atenta, representação e vínculo) mesmo com um livro de não-ficção.

Além das apresentações de capítulos lidos de livros escolhidos, são ainda realizados exercícios de escrita a cada aula. Os exercícios são propostos a partir de crônicas, por exemplo "Pá pá pá” de Luiz Fernando Veríssimo ${ }^{20}$ para se discutir formas de linguagem, ou "Mineirinho" de Clarisse Lispector $^{21}$ para uma discussão sobre excessos cometidos pelos seres humanos; contos como "Zaíta esqueceu de guardar os brinquedos" de Conceição Evaristo ${ }^{22}$, para trazer uma discussão sobre violência, preconceito e diferença social; ou poesias como "Guardar" de Antonio Cícero ${ }^{23}$ (1996), para se falar dos diferentes significados de uma palavra. Ainda são propostos exercícios de escrita a partir de alguns vídeos como a palestra TED "O perigo de uma História Única” de Chimamanda Nagozi Adi$\mathrm{chie}^{24}$, de forma a se falar também sobre preconceito.

Em uma outra dinâmica de ensino, são propostas leituras de imagens que podem ser obras de pintores atuais ou clássicos, ou cenas de cinema. O exercício de escrita proposto ocorre a partir de uma frase disparadora proposta após e se baseia no princípio da Literacia Visual ${ }^{25}$, incorporado pelas professoras a partir de curso realizado com o grupo da Dra. Isabel Fernandes da Faculdade de Letras da Universidade de Lisboa em 2018. Esses exercícios provocam reações muitas vezes inesperadas nos alunos, a partir das leituras posteriores do que escreveram e das diferentes histórias que imaginaram, trazendo a certeza de que a leitura, seja de textos ou de imagens, provoca diferentes sentimentos em cada um. Essas costumam ser as aulas que mais geram respostas positivas por parte dos alunos.

Ao final do curso solicita-se a cada um a indicação de três diferentes manifestações artísticas que eles acreditam poderem ser de bom uso na disciplina. E com uma discussão sobre a razão de suas escolhas encerra-se o curso. É importante dizer o quanto as professoras também aprendem a partir do

\footnotetext{
${ }^{18}$ Moacyr Scliar, A mulher que escreveu a Bíblia (São Paulo, Companhia das Letras, 1999, 2a reimpressão).

${ }^{19}$ Eckhart Tolle, O poder do agora (Rio de Janeiro, Sextante, 2000).

${ }^{20}$ Luis Fernando Veríssimo, Comédias para se ler na escola (Rio de Janeiro, Editora Objetiva, 2001).

${ }^{21}$ Clarice Lispector, Todas as crônicas (Rio de Janeiro, Editora Rocco, 2018).

${ }^{22}$ Conceição Evaristo, Olhos D'água (Rio de Janeiro, Editora Pallas, 2014).

${ }^{23}$ Antonio Cícero, Guardar (Rio de Janeiro, Editora Record, 1996).

24 Chimamanda Nagozi Adichie, O perigo de uma história única (TED Talk, 2014, https://www.ted.com/talks/chimamanda_ngozi_adichie_the_danger_of_a_single_story?language=pt).

${ }^{25}$ Isabel Capelloa Gil, Literacia Visual: estudos sobre a inquietude das imagens (Lisboa, Edições 70, 2011).
} 
material trazido pelos alunos, o que transforma essa disciplina numa via de mão dupla na relação aluno-professor.

Atualmente, a disciplina de Aperfeiçoamento da Linguagem ocorre também num novo curso de Odontologia da mesma escola; esse curso tem por característica possuir o mesmo ciclo básico dos cursos de medicina. Com a primeira turma, o trabalho de leitura foi realizado com "A Morte de Ivan Ilitch"26 e os demais exercícios já comentados. O final dessa primeira experiência foi a incorporação da escuta atenta ao paciente em trabalhos apresentados para outra disciplina, no qual os alunos falaram sobre a importância da atuação dos profissionais de Odontologia em equipes de Saúde da Família.

\section{Todo aluno tem uma história para contar: medicina narrativa em sala de aula}

Escrita e literatura desde sempre estiveram presentes na medicina, especialmente na formação dos futuros profissionais. Na Europa do século XIX a educação médica fazia uso das artes, através da literatura, da pintura e da música para compor uma educação ampla do médico, levando-o à leitura de textos clássicos e, consequentemente, a diversas produções literárias ${ }^{27}$.

Na segunda metade do século XX a literatura foi introduzida formalmente nas escolas médicas americanas, inicialmente em 1972 e, posteriormente em 1982, em uma escola médica de San Diego, por Lawrence Schneiderman - professor do departamento de medicina de família ${ }^{28}$.

Também no século XX, no Brasil, a importância das artes para a prática clínica vinha sendo defendida através do médico, professor e escritor Moacyr Scliar, que sustentava a importância da leitura e da escrita para a medicina. Scliar chamou a atenção para a forte relação entre a medicina e a literatura, fato verificado através das inúmeras obras literárias produzidas por médicos escritores, tais como Pedro Nava, Conan Doyle, João Guimarães Rosa, Oliver Sacks, Antônio Lobo Antunes, dentre tantos outros.

Literatura e medicina têm muitos pontos em comum, pois ambas lidam com a palavra e com histórias. Além disso, há uma mútua contribuição - a literatura faz uso das experiências médicas, da

\footnotetext{
${ }^{26}$ Leon Tolstoi, A morte de Ivan Ilicth (Porto Alegre, L\&PM Pockets, 2020).

${ }^{27}$ Moacyr Scliar, A Paixão Transformada - história da medicina na literatura (São Paulo, Companhia das Letras, 1996).

${ }^{28}$ Maria Auxiliadora De Benedetto "Entre dois continentes: literatura e narrativas humanizando médicos e pacientes”, O Mundo da Saúde, 34-3 (2010): 311-319.
} 
relação médico-paciente, do processo de adoecimento para sua criação ficcional, enquanto que a medicina tem na literatura uma forte contribuição para a formação médica, no que diz respeito ao desenvolvimento e aprimoramento das habilidades humanísticas necessárias à prática assistencial ${ }^{29}$.

É consenso o reconhecimento de um certo desencontro na relação médico-paciente atribuída, muitas das vezes, à primazia dos recursos tecnológicos na prática clínica e na crença absoluta na medicina, mais como ciência, do que como arte ${ }^{30,31}$.

Os cursos de graduação médica, acompanhando essa realidade, têm procurado enfatizar a importância da humanização do cuidado, estabelecendo para isso a inclusão de diversas disciplinas do eixo das humanidades médicas, tais como ética, bioética, sociologia, dentre outras. Dessa forma, a UNESA - Universidade Estácio de Sá, que oferece o curso de medicina desde 1997, incluiu na sua grade curricular a disciplina de Sociologia e Humanidades Médicas, a partir do primeiro semestre de 2016.

Desde então, a disciplina vem sendo ministrada de acordo com a metodologia baseada na construção teórico-prática da Medicina Narrativa, conforme desenvolvida pela médica e literata Rita Charon $^{2}$. Sendo assim, os conteúdos abordados, relacionados à história da medicina, à formação médica, à relação médico-paciente, ao processo de adoecimento, à morte e ao luto são discutidos tendo como recurso disparador a arte, através da literatura, pintura, cinema e música e da produção artística dos alunos, conforme será apresentado a seguir.

A disciplina tem início com as aulas sobre a história da medicina e a formação médica, abordadas a partir da exposição de pinturas clássicas que revelam os grandes momentos de desenvolvimento da medicina retratados, por exemplo, por Rembrandt em "Lição de Anatomia do Dr. Tulp" (1632) e, também através de filmes como "O Primeiro Ano" (França, 2019), "Hipócrates" (França, 2014) e "O Físico" (Alemanha, 2014).

Os demais temas - processo de adoecimento, relação médico-paciente, morte e luto - são apresentados e discutidos a partir da literatura ficcional, ou patografias, onde são usados livros, poemas, contos ou crônicas que tratam do tema. Ao final de cada aula é realizada uma oficina narrativa, conforme o modelo desenvolvido nos workshops de Medicina Narrativa, a saber: leitura atenta, frase disparadora, produção narrativa reflexiva e discussão.

\footnotetext{
${ }^{29}$ José Camargo, A interface da Medicina e da literatura in: Novis et al. Medicina Narrativa: a arte do encontro (Rio de Janeiro, Thieme Revinter, 2021).

${ }^{30}$ João Lobo Antunes, A nova medicina (Lisboa, FFMS, 2012).

${ }^{31}$ João Lobo Antunes, Ouvir com outros olhos (Lisboa, Gradiva Publicações, 2016).

${ }^{2}$ Ibid
} 
O livro “A Morte de Ivan Ilitch" - de Léon Tolstoi² é o que suscita um trabalho mais amplo em termos de produção artística e de narrativas. O livro é todo lido individualmente e, em conjunto, são lidos e discutidos alguns de seus trechos. Ao final do semestre os alunos realizam uma apresentação, em grupo, através de diferentes expressões artísticas - dramatização, música, poesia, pintura, ilustrações, esculturas, dentre outros recursos. Inicialmente os alunos, quando é proposta a realização desta atividade, mostram-se preocupados, pois muitos alegam não ter nenhuma habilidade artística. No entanto, ao final, todos se surpreendem com a capacidade criativa que surge a partir do estímulo oferecido. Muitos alunos conseguem inovar recontando a história, com bastante originalidade e das mais diferentes maneiras. Dessa forma, já foi possível presenciar - a criação de um instagram do Ivan Ilitch, onde o próprio Ivan relata o seu processo de adoecimento; a montagem de um programa de TV intitulado "casos de família", onde Ivan Ilich e seus familiares levam para o público os seus conflitos diante do adoecimento; poemas e músicas compostas especialmente para recontar a sua história; além de dramatizações onde Ivan Ilitch é trazido para os dias atuais e é atendido pelo SUS; ou ainda dramatizações feitas por bonecos de papel marché ou fantoches confeccionados pelos alunos.

Atualmente, após seis anos de realização deste trabalho, já chegamos ao total de 12 turmas, alcançando aproximadamente 360 alunos que participaram da disciplina. A seguir, apresentamos alguns depoimentos de alunos que podem ilustrar as suas considerações a respeito dos possíveis efeitos e contribuições das atividades propostas.

Depoimento 1: “A disciplina foi muito engrandecedora para mim tanto quanto pessoa, quanto futura profissional. ... me sensibilizou de forma mais humana nos assuntos que considerava essencial à objetividade e racionalidade, como morte e luto. ... me estimulou a escrever sobre meus problemas e angústias do mundo médico e pessoa...me preparou melhor para enfrentar as fragilidades emocionais, entendendo-as em primeiro lugar".

Depoimento 2: "Fiz a disciplina após ter passado por propedêutica, mas consigo fazer relação entre as duas, principalmente em um conto que lemos, sobre um homem desesperado por ter pego raiva".

Depoimento 3: "Sempre tive o hábito de ler, mas desde o vestibular não me permitia ter tempo para ler nada que me gerasse lazer. A disciplina me fez repensar a minha conduta. A leitura é minha maior aliada, principalmente para conter a ansiedade. Agora a escrita foi o que mais me tocou, desde que fui estimulada a escrever (...) eu consegui perceber que a escrita ajuda a organizar sentimentos e pensamentos. Nos meus momentos de angústia a escrita é minha melhor amiga. Depois da disciplina já escrevi diversos poemas."

Depoimento 4: "Era um momento do meu dia leve e ao mesmo tempo reflexivo. Um dos principais momentos foi quando li um texto que falava de uma experiência minha com a morte e onde perceber que toquei muitas pessoas de forma profunda, repercutiu até mesmo fora de sala e eu me senti ouvida pelos colegas de classe que estão sempre em uma competição infernal para ser o melhor médico, melhor da turma, sempre em disputas por pódios invisíveis. Pude enxergar a humanidade neles também”. 
Depoimento 5: "Lembro da sensação de alívio que eu tinha do dia que havia a disciplina. Era um tempo em que eu estava completamente presente na sala de aula, com vontade de discutir os assuntos levantados. No ciclo básico da faculdade as disciplinas eram maçantes e era preciso memorizar conteúdos infinitos diariamente, sem qualquer exercício de critica ou debate. Ter a oportunidade de poder discutir sobre o contexto de todo aquele aprendizado foi extremamente favorável para meus estudos".

Depoimento 6: "A disciplina me ajudou a desenvolver a empatia e a capacidade de lidar com os pacientes, bem como a enfrentar a morte de forma mais madura e sensata".

Depoimento 7: "Lembro de uma redação que fizemos logo no início da disciplina, nela tivemos que relatar a morte de alguém próximo... escrever me fez recordar de acontecimentos que tinham se perdido".

Depoimento 8: “(...) devia ser incluída na grade curricular. Além de ser leve e super bacana (...). Estimula o aluno a pensar fora da caixinha e a perceber que todo paciente tem uma história pra contar".

Os depoimentos apresentados reforçam a importância da Medicina Narrativa na Educação Médica. Despertar no aluno a percepção de que todo paciente tem uma história para contar deve ser, sem dúvida, um dos objetivos da nossa proposta e, ao que tudo nos indica, podemos alcançá-lo quando também valorizamos as histórias dos nossos alunos.

\section{Médicos e estudantes contando casos}

Médicos e estudantes de medicina costumam gostar de contar casos trazidos de suas vivências profissionais. De algum modo, contar essas histórias sobre vidas, pessoas e adoecimentos, vai sendo substituído, durante o curso de medicina, por um formato de apresentação padrão, dos chamados casos clínicos, nos quais desaparecem os nomes e ampliam-se as siglas para indicar queixas e sinais físicos. Neste relato de experiência está descrito o desenvolvimento de uma disciplina curricular regular do curso de medicina da Universidade Estácio de Sá (UNESA), no Rio de Janeiro, envolvendo todo o universo de alunos das turmas, a cada período, com professores de diferentes áreas, em que a inclusão da construção de narrativas tem sido desenvolvida.

$\mathrm{Na}$ estrutura curricular da graduação em medicina da UNESA estão estabelecidas disciplinas denominadas Seminários Integrados, oferecidas como obrigatórias do $1^{\circ}$ ao $8^{\circ}$ períodos. No $7^{\circ}$ período, a disciplina de Seminário Integrado VII tem como campo estruturante o da bioética aplicada à formação e prática médica, organizada com grupos de 10 alunos, que são orientados por um professor relacionado a uma das disciplinas regulares do período, visando a realização de um trabalho por grupo, a ser apresentado ao final. A partir do ano de 2017, houve uma proposição docente de que no desenvolvimento dos diferentes trabalhos fossem elaboradas narrativas de casos em formas de livre escolha. Um dos destaques dessa experiência diz respeito ao fato de que participam do Seminário 
Integrado VII cerca de 12 professores, na maioria médicos de diferentes especialidades e sem vinculação direta com a bioética. Além da vantagem de variedade nos casos que são apresentados, pode ser vista como uma estratégia de desenvolvimento docente, na medida em que estes também passam a agregar competências articuladas às humanidades.

Professores e estudantes são provocados a apresentar os casos como narrativas de vivências, histórias de pessoas, sejam essas baseadas em situações reais ou ficcionais. Criatividade e emoções estão liberadas, sendo altamente recomendado o protagonismo dos estudantes nas escolhas de fatos, temas, referências e formato das narrativas. A livre escolha temática e dos casos pelos estudantes aponta um ótimo potencial para o envolvimento pleno dos membros do grupo no trabalho. Há quatro anos essa atividade curricular se desenvolve e a cada período se consolida o caminho escolhido, visando a ampliação de vivências com diferentes formas de narrativas. Identifica-se como uma estratégia de inserção curricular que não somente amplia as possibilidades da bioética na educação médica, como também está voltada ao desenvolvimento docente em cenário interdisciplinar e democrático.

Os trabalhos finais da disciplina são apresentados numa estrutura onde está sugerida a apresentação do caso em formato de narrativa livre. Além do texto, os grupos têm 20 minutos para uma apresentação final, em qualquer formato que escolham, seguida de discussão com a turma e professores por mais 20 minutos. Desde 2020 que as atividades de encontros semanais com os professores orientadores, assim como as de apresentação final, têm se mantido através da plataforma digital de modo remoto e síncrono, por conta das recomendações decorrentes do quadro sanitário da pandemia da Covid-19.

Além dos textos com as narrativas de casos, os grupos utilizam várias linguagens nas apresentações: exposições com apoio em formatação gráfica variada; referências de filmes, literatura e outras artes; dramatização ao vivo ou apresentada em filmes produzidos pelos alunos; metodologias interativas, entre outras, com qualidade, beleza e criticidade impressionantes.

Um painel de assuntos e casos, selecionados como exemplos para esse relato de experiência, nos aponta que situações tão complexas da prática médica podem ser experimentadas de outro modo, quando contamos histórias de pessoas, famílias e profissionais, trazendo-nos dimensões de afetividade e empatia, não dispensáveis nas boas práticas médicas. Os títulos e as partes de textos dos trabalhos, apresentados a seguir, constituem material do arquivo da coordenação da disciplina e estão aqui descritos de modo adaptado, considerando as reservas necessárias à preservação dos direitos originais de autoria. Entretanto, mesmo nesta forma adaptada, permitem concluir esse relato de experiência com narrativas, objetivo central deste artigo. 
Um relato de caso na psiquiatria: "Numa tarde nublada na cidade do Rio de Janeiro com temperatura agradável o suficiente para qualquer tipo de roupa.... a o encerrar a conversa com aquela mulher de 30 anos, com uma despedida um pouco mais calorosa do que um até logo, ela veio em minha direção com um abraço.

Desafios no tratamento do idoso renal crônico: “Ela alega que esse tratamento mudaria a dinâmica da casa, incluindo a alimentação e que mais custos com transporte, cuidadora, entre outros fatores, inviabilizariam a terapia. Além disso, alega já ter idade muito avançada para se submeter a um tratamento tão complexo......"

Aborto em caso de estupro: "Mirela sonhou tanto com a sua aprovação no vestibular de medicina............ Depois de tanto esforço e persistência, a jovem de 18 anos decidiu comemorar com amigas indo a uma festa. Na hora da saída, uma de suas amigas não a encontra e as outras pessoas não a viram pelo local......"

Conflitos na ordem de não ressuscitar: "Nosso paciente, a quem vamos chamar de Thiago, tem 75 anos, é branco e do sexo masculino. Ele é do sexo masculino. Deu entrada na emergência de um hospital geral no Rio de janeiro, aonde chega inconsciente, desidratado e em fibrilação atrial. Possui uma tatuagem no corpo onde está registrado que não deseja ser reanimado, em caso de parada cardiaca......"

Dilemas no cuidado da pessoa idosa: “Na manhã do dia 06/08 do ano seguinte, seu sobrinho entrou em contato com sua médica pois, ao visitar sua tia, achou que ela estava prostrada e com dificuldade para respirar....... A doutora então explicou para o sobrinho e para a própria paciente que indicava internação para tratamento hospitalar, a que a paciente recusou prontamente, argumentando que já estava muito velha, que sua vida não tinha mais sentido......"

Racismo nas instituições de saúde: “Como mulher negra, na faculdade descobri o quão violenta e racista a medicina pode ser. Na falta de outros colegas negros na minha turma, na falta de professores negros, fui percebendo que havia um lugar para os corpos negros no ambiente médico, e esse lugar era exclusivamente o lugar dos corpos a serem estudados, seja no anatômico ou como pacientes"

Transfusão sanguínea e testemunhas de Jeová: “Após avaliação médica e dos exames laboratoriais, os médicos consideram que a transfusão de sangue era o melhor tratamento. Por razões religiosas, a família é Testemunha de Jeová, os pais recusam e não autorizam o tratamento. Sua crença 
condena a hemotransfusão, e caso a criança passe pelo procedimento seria expulsa da comunidade religiosa...."

Cuidados Paliativos e Autonomia: "Então foi assim que se sentiu Ivan Ilitch, pensou seu Horácio, trabalhador da Biblioteca Nacional, ao perceber que passava, enfim, pelo seu processo de morte. Apaixonado por livros e por seu trabalho, sempre carregava consigo algum exemplar. Morador de Olaria, tinha no transporte público um momento de relaxamento de seus afazeres e acesso a outra realidade. Ao ler a morte de Ivan Ilitch, aos 30 anos, ressignificou sua ideia do que seria uma morte digna e, desde então, construiu sua opinião sobre como lidaria com seu processo.

\section{Conclusão}

A valorização das narrativas e de outros aspectos relacionados às humanidades na formação médica surgiu como uma tentativa de resposta à pretensa neutralidade e ao distanciamento envolvidos no cuidado em saúde. Diante desse cenário, os cursos de graduação médica foram impulsionados a refletir sobre novas estratégias que pudessem contribuir para uma ampla formação dos profissionais, estabelecendo mudanças curriculares que, como já mencionado, culminaram na inserção de novas disciplinas e metodologias de ensino.

Uma das importantes iniciativas foi a aproximação entre medicina e literatura. A estruturação de uma fundamentação teórica e metodológica desenvolvida por Charon, organizou um campo de conhecimentos nomeado por ela de medicina narrativa. O seu modelo de workshops foi se expandindo e impulsionando a sua ampla utilização nos diversos espaços acadêmicos. O objetivo deste artigo, através de relatos de experiências, foi apresentar a utilização de narrativas como espaço de partilhas do sensível em diferentes cenários, atividades, propostas e recursos, que alcançaram diferentes resultados, de acordo com cada realidade, preferências e estilos dos grupos, seus coordenadores e seus participantes.

A arte de uma maneira geral, em suas diversas linguagens de expressão, e as estratégias que favoreçam o desenvolvimento de competência narrativa são importantes recursos no desenvolvimento de habilidades e competências que podem auxiliar na promoção do cuidado e no favorecimento das relações em saúde. Não podemos afirmar que a realização dessas atividades será capaz de beneficiar a todos os envolvidos. Ou mesmo por quanto tempo os efeitos conquistados serão mantidos. Atualmente inúmeras pesquisas têm sido realizadas, buscando mensurar e apresentar os efeitos da utilização de recursos artísticos na graduação médica e, de fato, os resultados são promissores. No entanto, entendendo que a medicina trata de incertezas, muito mais do que de certezas, precisamos 
destacar que também aqui, não há garantias. Mas a arte pode abrir inúmeras possibilidades, estimulando a criatividade e a inovação e, por isso, apostamos no seu efeito humanizador, como uma possibilidade para lidar com o que há de humano, demasiadamente humano, em cada um de nós.

\section{Sugestões de materiais para atividades de Medicina Narrativa}

\section{Producão Audiovisual}

Aquela Conversa - Programas de TV sobre promoção da saúde (MultiRio/PCRJ) https://youtube.com/playlist?list=PLPdaje007PViI6MFnNJ0381s7jFvVpAQa

Começo da Vida (trailer) - Tema: Primeira Infância. Maria Farinha Filmes. https://www.youtube.com/user/mariafarinhafilmes

Criança, a Alma do Negócio (trailer) - Tema: O impacto da publicidade na alimentação e na saúde das crianças. Maria Farinha Filmes. https://www.youtube.com/user/mariafarinhafilmes

Gentileza - Vídeo elaborado pelos jovens do projeto RAP da Saúde (SMS-RJ e Cedaps) - Tema: Preconceitos https://youtu.be/0yxcgyL7wLU

Grey’s Anatomy - Série sobre temas médicos. Disponível no Netflix

Janela da alma - Documentário de João Jardim e Walter Carvalho. Tema: Pessoas com deficiência visual falam como se vêem e como percebem o mundo. https://youtu.be/_I917upG0DI

Nossas Verdades - Vídeo elaborado pelos jovens do projeto RAP da Saúde (SMS-RJ e Cedaps) Tema: A primeira vez https://youtu.be/rLkeJSwYHUA

Ter.a.pia. - Pessoas contam histórias enquanto lavam a louça https://www.youtube.com/channel/UChmjYEZRia5JAmLi1aFaMlg

\section{Referências bibliográficas}

Adichie, Chimamanda. O perigo de uma história única. TED Talk, 2014, https://www.ted.com/talks/chimamanda_ngozi_adichie_the_danger_of_a_single_story?language $=\mathrm{pt}$

Brasil. Ministério da Educação. Parecer CNE/CES 116, de 3 de abril de 2014. Diretrizes Curriculares Nacionais do Curso de Graduação em Medicina.

Brasil. Ministério da Educação. Parecer CNE/CES 4, de 7 de novembro de 2001. Diretrizes Curriculares Nacionais do Curso de Graduação em Medicina.

Camargo, José. A interface da Medicina e da literatura. In: Ana Luiza Novis, Fátima Geovanini e Lorraine Veran (eds.): Medicina Narrativa a arte do encontro. Rio de Janeiro: Thieme Revinter, 2021.

Capelloa Gil, Isabel. Literacia Visual: estudos sobre a inquietude das imagens. Lisboa: Edições 70, 2011. 
Casal, Teresa. Narrativa e Medicina: A Perspectiva da Primeira Pessoa no Encontro Clínico. In: Narrativa e Bioética, org. António Barbosa. Lisboa: Faculdade de Medicina de Lisboa: Centro de Bioética; 2015, p. 55-71.

Charon, Rita, Sayantani Dasgupta, Nellie Hermann, Craig Irvine, Eric C. Marcus, Edgar R. Colón, Danielle Spencer, Maura Spiegel. The Principles and Practice of Narrative Medicine - New York, NY: Oxford University Press, 2017.

Charon, Rita. Narrative Medicine: a Model for Empathy, Reflection, Profession and Trust. JAMA 286 (2001):1897-902.

Cícero, Antonio. Guardar. Rio de Janeiro: Editora Record, 1996.

De Benedetto, M.A.C. Entre dois continentes: literatura e narrativas humanizando médicos e pacientes. O Mundo da Saúde, 34-3 (2010): 311-319.

Evaristo, Conceição. Olhos D'água. Rio de Janeiro: Editora Pallas, 2014.

Freire Paulo. Pedagogia da autonomia: saberes necessários à prática educativa. Rio de Janeiro: Editora Paz e Terra, 2013.

Haidet, Paul, Jody Jarecke, Nancy Adams, Heather Stuckey, Michael Green, Daniel Shapiro, Cayla Teal, Daniel Wolpaw. A guiding framework to maximise the power of the arts in medical education: a systematic review and metasynthesis. Med Educ 50, 3 (2016): 320-31.

Lobo Antunes, João. A nova medicina. Lisboa: FFMS, 2012.

Lobo Antunes, João. Ouvir com outros olhos. Lisboa: Gradiva Publicações, 2016.

Mallet, Ana L.R. e Andrade, L.P.L.S. (eds). Literatura e medicina: uma experiência de ensino. Rio de Janeiro: Livros Ilimitados, 2017.

Ranciére, Jacques. A partilha do sensível. São Paulo: Editora 34, 2009.

Sanders, Lisa. Todo paciente tem uma história para contar. Rio de Janeiro: Zahar, 2009.

Santos, R.C. Modos de saber, modos de adoecer: o corpo, a arte, o estilo, a história, a vida, o exterior. Belo Horizonte: Ed. UFMG, 1999.

Saramago, José. As Intermitências da Morte. São Paulo: Companhia das Letras, 2005.

Scliar, Moacyr. A mulher que escreveu a Bíblia. São Paulo: Companhia das Letras, 1999, 2a reimpressão.

Scliar, Moacyr. A Paixão Transformada - história da medicina na literatura. São Paulo: Companhia das Letras, 1996.

Tolle, Eckhart. O poder do agora. Rio de Janeiro: Sextante, 2000.

Tolstoi, Leon. A morte de Ivan Ilicth. Porto Alegre: L\&PM Pockets, 2020.

Veríssimo, Luis F. Comédias para se ler na escola. Rio de Janeiro: Editora Objetiva, 2001. Lispector, Clarice. Todas as crônicas. Rio de Janeiro: Editora Rocco, 2018. 